Archive for

Organic Chemistry

Arkivoc 2018, part ii, 330-343

\title{
Synthesis and structures of zwitterionic polymers to induce electrostatic interaction with PDMS surface treated by air-plasma
}

\author{
Mutsuo Tanaka, * Yoshiki Hirata, Takahiro Sawaguchi, and Shigeru Kurosawa*
}

Health Research Institute, Advanced Industrial Science and Technology (AIST), 1-1-1, Higashi, Tsukuba, Ibaraki, 305-8566, Japan

Email: mutsuo-tanaka@aist.go.jp

\section{Dedicated to Professor Kenneth K. Laali on the occasion of his $65^{\text {th }}$ anniversary}

Received 08-28-2017

Accepted $01-30-2018$

Published on line $03-04-2018$

\begin{abstract}
Various zwitterionic polymers, sulfobetaine and phosphoryl choline derivatives were synthesized in order to investigate zwitterionic polymer structures toward surface modification of PDMS, where the adsorption of zwitterionic polymers on polydimethylsiloxane surface treated with air-plasma was induced by the electrostatic interaction,. The electrostatic interaction was evaluated with hydrophilicity. The results suggested that a sulfobetaine polymer with higher molecular weight, lower molecular weight distribution, and shorter alkyl chain afforded high electrostatic interaction. A sulfobetaine polymer bearing phenylazide group showed similar electrostatic interaction with the PDMS surface, and it is a promising material for surface modification ofpolydimethylsiloxane.
\end{abstract}

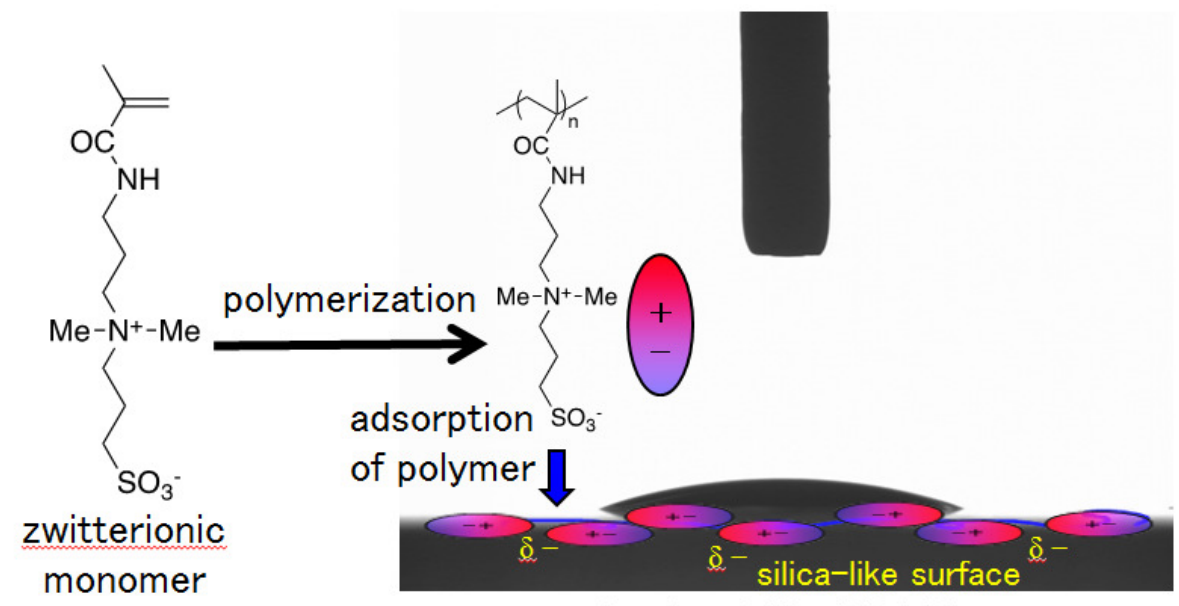

hydrophilic PDMS

Keywords: Surface modification, zwitterionic, polymer, electrostatic, sulfobetaine 


\section{Introduction}

Zwitterionic polymers whose monomers have positive and negative charges in the same molecule are well known as one of biocompatible materials. Among zwitterionic polymers, phosphoryl choline and sulfobetaine groups are common as functional groups. Those polymers are really attractive as surface modification materials in biosensor field. The surfaces modified with those polymers show high resistance against nonspecific adsorption of proteins with hydrophilicity, ${ }^{1-5}$ where these surface properties are highly recommended to realize high performance for biosensor systems. Therefore, various zwitterionic polymers have been synthesized and evaluated for that purpose. While zwitterionic polymers are used as coating materials, ${ }^{6-10}$ it is reported that interfacial polymerization of zwitterionic monomers by atom transfer radical polymerization (ATRP) affords a surface modified with polymer brushes to show high resistance against non-specific adsorption of proteins with hydrophilicity. ${ }^{11-16}$

On the other hand, the application of micro flow channel for biosensor system has been studied extensively since micro flow channel has potential to enhance performance of sensors. ${ }^{17-19}$ Polydimethylsiloxane, PDMS is the most common material to fabricate micro flow channel. However, there is a critical problem to use PDMS as material for micro flow channel. The surface of polydimethylsiloxane (PDMS) is strongly hydrophobic to disturb flow of aqueous samples due to the surface tension when the micro flow channel is narrow. As it is reported that PDMS surface is oxidized by plasma, corona discharge, and UVtreatment to form a silica-like layer to show hydrophilicity, ${ }^{20-26}$ many attempts of surface treatments to obtain hydrophilic PDMS surface were conducted. However, the PDMS surface recovered hydrophobicity soon because of molecular mobility of PDMS. ${ }^{20-24}$ Only a few examples of surface modification using interfacial polymerization are reported to afford hydrophilic PDMS surface without recovering of hydrophobicity. ${ }^{27,28}$

There are some intriguing reports about coating methods for silica surface, where the coating with cationic polymers is successful to afford a durable modified surface due to electrostatic interaction ${ }^{29,30}$ because silica surface is negatively charged. ${ }^{31}$ In polymer coating, the electrostatic interaction sometimes plays crucial role to afford a durable modified surface by formation of polyion-complexes. ${ }^{32-34}$ Furthermore, it is reported that annealing treatment of coating surface with polymers enhances electrostatic interaction by structural arrangement of polymers due to their flexibility. ${ }^{35}$ The surface of PDMS treated by air-plasma is known to be silica-like, but the molecule at the surface seems to be flexible enough to recover hydrophobicity. ${ }^{20-24}$ Therefore, we expected that zwitterionic polymers might have some potential to interact with the PDMS surface by the electrostatic interaction similar to cationic polymers. The examination revealed that zwitterionic polymers are adsorbed on the PDMS surface treated with air-plasma to afford hydrophilic surface. $^{36}$ In this work, we studied on the relationship between structures of zwitterionic polymers and electrostatic interaction toward modification of PDMS surface.

\section{Results and Discussion}

Zwitterionic polymers synthesized in this work are shown in Scheme 1,. Synthesis procedures are described in Experimental Section. In cases of sulfobetaine monomers, we adopted amide bond to combine sulfobetaine moiety with methacryl moiety in molecular design, because amide bond resists non-specific adsorption of proteins ${ }^{37}$ and hydrolysis more effectively than ester bond under common conditions. 


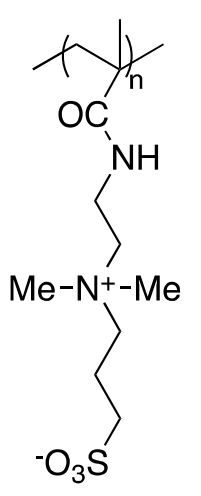

C2SB

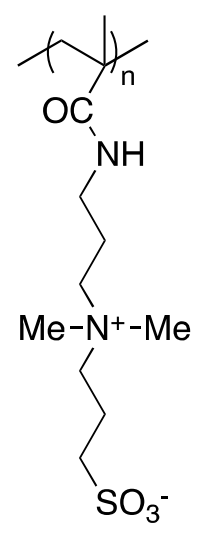

C3SB

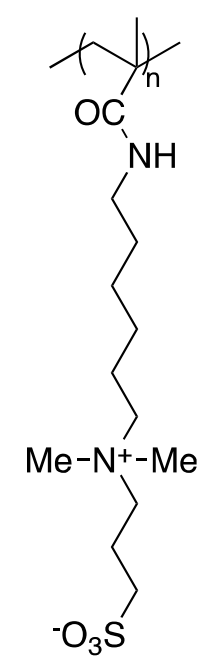

C6SB

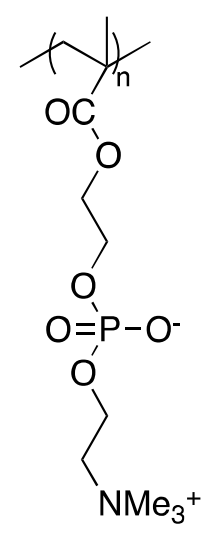

MPC

Scheme 1. Synthesized Zwitterionic Polymers.

In our previous work, ${ }^{36}$ we found that the adsorption of sulfobetaine and phosphoryl choline polymers on the PDMS surface treated with air-plasma, afforded hydrophilic PDMS surface. The adsorption of zwitterionic polymers on the PDMS surface was strong enough to resist ultrasonic cleaning in water. The hydrophilicity of PDMS surface was kept even after 1 month of the modification, while the PDMS surface only treated with air-plasma recovered hydrophobicity within four days due to molecular mobility of PDMS as reported before. ${ }^{20-26}$ The results suggest that the zwitterionic polymers were adsorbed on the PDMS surface treated with air-plasma to suppress molecular mobility of PDMS effectively by the electrostatic interaction as expected. In control experiments, the PDMS surface modified with a monomer solution of C3SB by the same procedure, recovered hydrophobicity soon. Therefore, it is evident that the adsorption of zwitterionic polymers on the treated PDMS surface is derived from polymer effect, and the electrostatic interaction is strong enough to suppress molecular mobility of PDMS leading to a durable hydrophilic surface as illustrated in Figure 1.

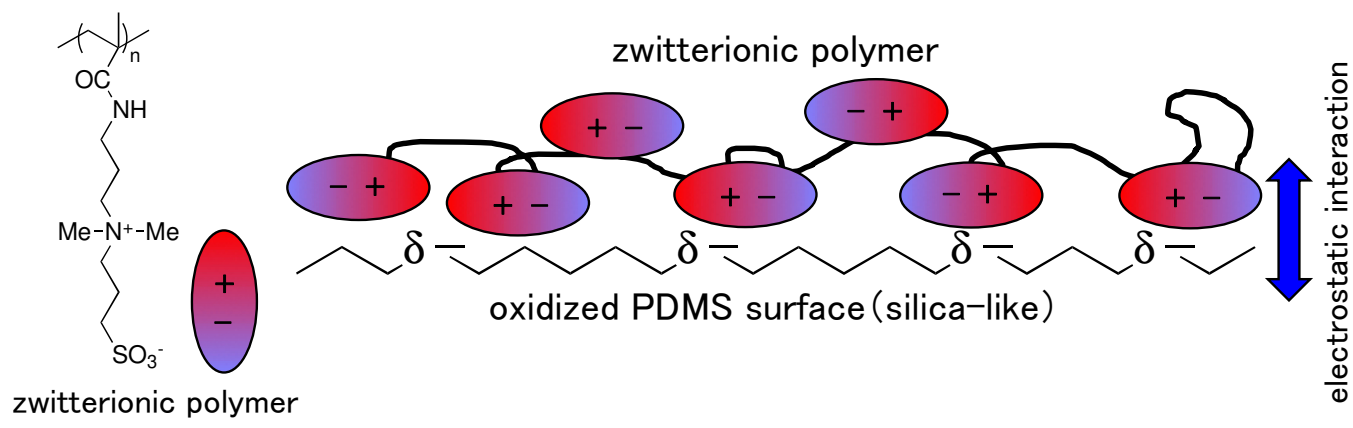

Figure 1. Schematic Diagram of Adsorbed Zwitterionic Polymer.

It is known that molecular mobility depends on temperature and it is enhanced at higher temperature. Therefore, in order to evaluate strength of the electrostatic interaction, heat treatment was applied to the PDMS modified with zwitterionic polymers, and the shift in contact angle was examined. The heat treatment conditions were at $60{ }^{\circ} \mathrm{C}$ for $12 \mathrm{~h}$ and at $100{ }^{\circ} \mathrm{C}$ for $5 \mathrm{~h}$. The contact angles are summarized in Table 1 with 
molecular weight (M.W.) and molecular weight distribution (M.W.D.) for zwitterionic polymers. With treatment at $60{ }^{\circ} \mathrm{C}$ for $12 \mathrm{~h}$, the PDMS modified with MPC showed significant increase in contact angle, and the contact angle of PDMS modified with C6SB increased moderately. However, the PDMS modified with C2SB and C3SB did not show meaningful shift in contact angle under this condition. The results showed that the electrostatic interaction with C2SB and C3SB is stronger than that with C6SB and MPC. Then, the PDMS modified with C2SB and C3SB were exposed a harsher condition, at $100{ }^{\circ} \mathrm{C}$ for $5 \mathrm{~h}$. In Table 1 , the contact angle for C3SB was marginally lower than that for C2SB. Taking the polymer effect into account, this result does not indicate that C3SB has superior effect to suppress molecular mobility of PDMS by the electrostatic interaction compared with C2SB because the molecular weight of C3SB is far greater than that of C2SB.

Table 1. Contact angle shift by heat treatment

\begin{tabular}{cccccc}
\hline polymer & none & C2SB & C3SB & C6SB & MPC \\
\hline r.t., 4days & $95.2 \pm 0.6$ & $12.8 \pm 3.4$ & $14.1 \pm 6.2$ & $14.0 \pm 4.7$ & $21.9 \pm 6.8$ \\
$60{ }^{\circ} \mathrm{C}, 12 \mathrm{~h}$ & - & $13.8 \pm 1.9$ & $14.6 \pm 3.8$ & $32.7 \pm 2.7$ & $48.0 \pm 8.3$ \\
$100{ }^{\circ} \mathrm{C}, 5 \mathrm{~h}$ & - & $33.4 \pm 6.0$ & $25.5 \pm 4.8$ & - & - \\
M.W. & - & 17000 & 41000 & 19000 & 67000 \\
M.W.D. & - & 12.2 & 9.3 & 8.9 & 8.8 \\
\hline
\end{tabular}

Subsequently, the influence of the polymer effect on the electrostatic interaction was examined by using various C2SB and C3SB polymers, being different in molecular weight and molecular weight distribution. In the polymer synthesis, a common polymerization method using various amount of azobisisobutyronitrile (AIBN) was employed. In the case of C2SB monomer, there was some difficulty to obtain various polymers because of high reactivity of the monomer. To the contrary, C3SB monomer afforded various polymers in the molecular weight distribution, which decreased significantly with the decrease of AIBN amount. However, the molecular weights for the obtained C3SB polymers were between $30000 \sim 40000$ regardless of the AIBN amount. Attempts to obtain C3SB polymers with higher molecular weight by ATRP were failed. Therefore, we examined the mechano-chemical reaction with C3SB monomer, in which a radical is formed mechanically to induce polymerization reaction in solid phase. ${ }^{38,39}$ The obtained sulfobetaine polymer, C3SB-M had the highest molecular weight, where the molecular weight was 78000 . This result implies that the mechanochemical reaction is useful to obtain high molecular weight polymers.

The contact angles for the PDMS, modified with those polymers, were measured after heat treatment at $100{ }^{\circ} \mathrm{C}$ for $5 \mathrm{~h}$. The molecular weight and molecular weight distribution for the obtained polymers are summarized in Table 2 with the contact angles. The contact angles in Table 2 showed that the difference in both molecular weight and molecular weight distribution influences on the electrostatic interaction significantly. In Table 2, the contact angle for C3SB-M was the lowest indicating that higher molecular weight induces strong electrostatic interaction to suppress the molecular mobility of PDMS. On the other hand, comparison among the C3SB polymers synthesized by AIBN method demonstrated that polymers with narrower molecular weight distribution is more effective to suppress the molecular mobility of PDMS by the strong electrostatic interaction because the contact angle decreased with narrower molecular weight distribution. In addition, the comparison among C2SB-2, C3SB, and C3SB-2 suggested that C2SB could induce 
stronger electrostatic interaction than C3SB when molecular weight and molecular weight distribution were the same. Therefore, the order of effect to suppress the molecular mobility of PDMS by the electrostatic interaction was C2SB > C3SB > C6SB reflecting to the length of alkyl chains between sulfobetaine and methacryl groups. These tendencies show that zwitterionic polymers with higher molecular weight, narrower molecular weight distribution, and shorter alkyl chain are more effective to suppress the molecular mobility of PDMS being proportional to strength of the electrostatic interaction.

Table 2. Contact angles depending on M.W. and M.W.D.

\begin{tabular}{cccccccc}
\hline polymer & C2SB & C2SB-2 & C3SB & C3SB-2 & C3SB-3 & C3SB-4 & C3SB-M \\
\hline M.W. & 17000 & 22000 & 41000 & 29000 & 33000 & 38000 & 78000 \\
M.W.D. & 12.2 & 10.1 & 9.3 & 8.1 & 5.8 & 4.9 & 9.6 \\
$\begin{array}{c}\text { r.t., } \\
\text { 4days }\end{array}$ & $12.8 \pm 3.4$ & $9.2 \pm 2.6$ & $14.1 \pm 6.2$ & $13.7 \pm 2.3$ & $10.4 \pm 3.3$ & $8.5 \pm 2.4$ & $8.0 \pm 1.6$ \\
$100^{\circ} \mathrm{C}, 5 \mathrm{~h}$ & $33.4 \pm 6.0$ & $22.4 \pm 2.4$ & $25.5 \pm 4.8$ & $22.5 \pm 5.3$ & $18.3 \pm 6.7$ & $14.6 \pm 4.6$ & $14.4 \pm 3.8$ \\
\hline
\end{tabular}

The polymerization was carried out using C2SB monomer $(5 \mathrm{mmol})$ and methanol $(45 \mathrm{~mL})$ at $60^{\circ} \mathrm{C}$ for $12 \mathrm{~h}$ in the presence of AIBN $(0.25$ and $0.05 \mathrm{mmol})$ for C2SB and C2SB-2, respectively. In the case of C3SB monomer $(5 \mathrm{mmol})$, the polymerization was carried out using methanol $(30 \mathrm{~mL})$ at $60^{\circ} \mathrm{C}$ for $12 \mathrm{~h}$ in the presence of AIBN (0.25, 0.1, and $0.05 \mathrm{mmol})$ for C3SB and C3SB-2, C3SB-3, and C3SB-4, respectively. C3SB-M represents the mechano-chemical polymerization.

Generally, in the surface modification, formation of covalent bond between substrate and the surface modification material is desirable for robust modification. Therefore, a sulfobetaine copolymer bearing phenylazide group to form covalent bond by UV light irradiation ${ }^{40,41}$ was synthesized (Scheme 2). After 4 days of modification with the copolymer, the contact angle was $14.8^{\circ}$ in which the copolymer showed similar electrostatic interaction with the PDMS surface. After UV-light irradiation, the PDMS surface still kept high hydrophilicity with contact angle $18.2^{\circ}$ although slight increase was observed. Similarly, in control experiments using C3SB, UV-light irradiation induced some increase of contact angle. Therefore, the increase of contact angle was caused by UV light irradiation, but not by covalent formation of the copolymer. The results imply that zwitterionic copolymer bearing a functional group to form covalent bond is promising material for surface modification of PDMS.

We also examined the surface roughness of PDMS treated with air-plasma (100W) using atomic force microscope (AFM) as surface roughness is known to influence significantly the hydrophilicity. The AFM observation showed that the surface of PDMS became smooth by air-plasma treatment, as the surface roughness (Ra) of PDMS was decreased from $1.3 \mathrm{~nm}$ to $0.4 \mathrm{~nm}$ (Figure 2). Therefore, it is obvious that the hydrophilicity of modified PDMS surface reflects properties of the zwitterionic polymers adsorbed on the PDMS surface but not surface roughness of PDMS. Furthermore, influence of air-plasma power for surface treatment on contact angle shift was examined. The surface treatment of PDMS was conducted with100W and $200 \mathrm{~W}$ air-plasma power, and the modified PDMS was treated at $100^{\circ} \mathrm{C}$ for $5 \mathrm{~h}$. The contact angles after 4 days of the modification at room temperature were $14.1 \pm 6.2^{\circ}$ and $9.6 \pm 1.0^{\circ}$ with $100 \mathrm{~W}$ and $200 \mathrm{~W}$ air-plasma power, respectively, showing that hydrophilicity of PDMS surface was enhanced by higher air-plasma power. 
After heat treatment, the contact angles shifted to $25.5 \pm 4.8^{\circ}$ and $27.2 \pm 7.2^{\circ}$ for $100 \mathrm{~W}$ and $200 \mathrm{~W}$ air-plasma power, respectively. The shift of contact angle is more noticeable for $200 \mathrm{~W}$ air-plasma power. The result implies that the harsher surface treatment with air-plasma afforded more hydrophilic PDMS surface but durability of the hydrophilic PDMS surface is not always proportional to the hydrophilicity. This tendency is coincident that the harsher surface treatment not only forms thicker silica-like layer to show hydrophilicity but also causes degradation of polymer network with formation of mobile species to lead recovery of hydrophobi city as reported before. ${ }^{20-23}$

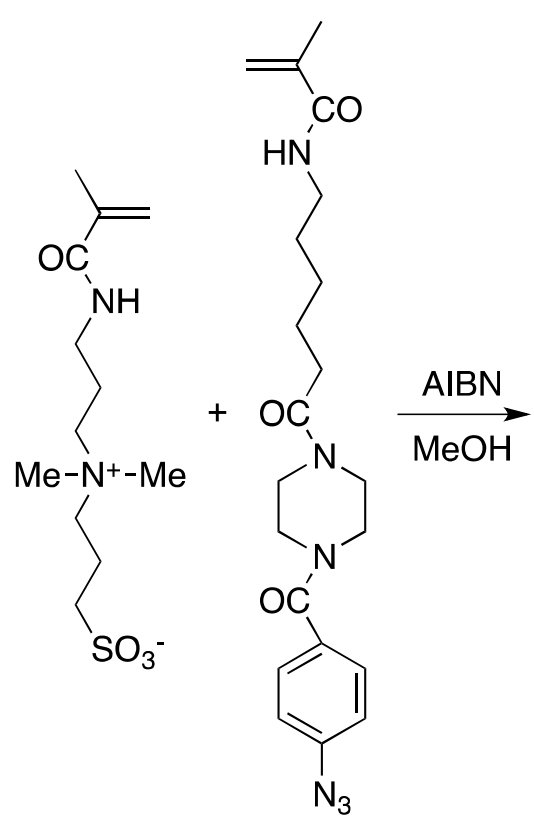<smiles>CCC(C)(C)CC(C)(C)CC(C)(C)C=O</smiles>

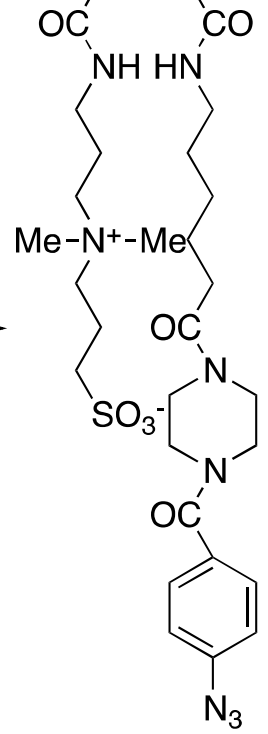

Scheme 2. Synthesis of Zwitterionic Copolymer.

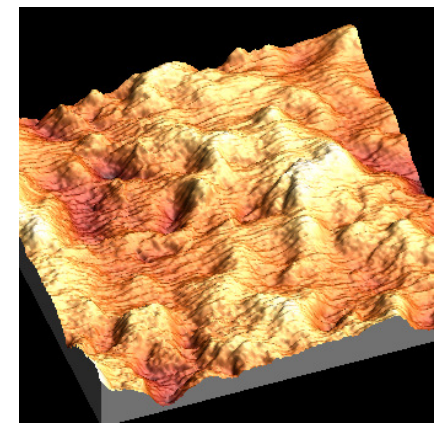

$\mathrm{Ra}=1.30 \mathrm{~nm}$ before UV treatment

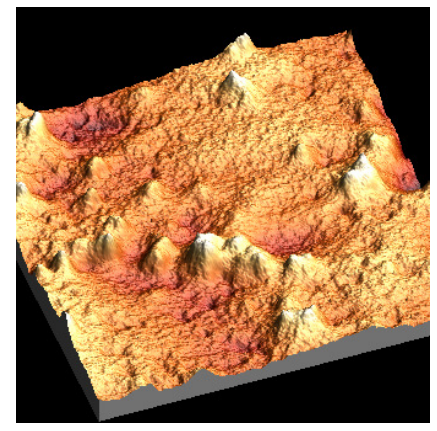

$\mathrm{Ra}=0.64 \mathrm{~nm}$ after UV treatment

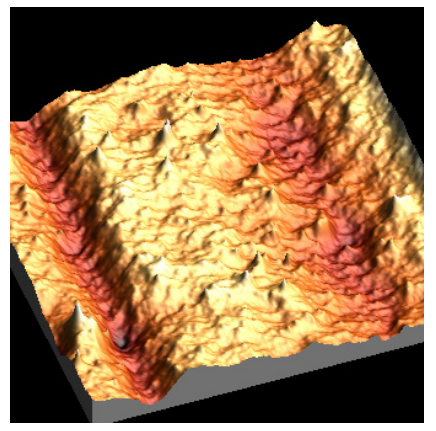

$\mathrm{Ra}=0.39 \mathrm{~nm}$ after C3SB modification

Figure 2. AFM Imags of PDMS.

\section{Conclusions}

It was found that the adsorption of zwitterionic polymers occurs on PDMS surface treated with air-plasma to suppress molecular mobility of PDMS by the electrostatic interaction, and a sulfobetaine polymer with higher 
molecular weight, lower molecular weight distribution, and shorter alkyl chain affords stronger electrostatic interaction. The PDMS surface modified with sulfobetaine polymers is quite durable to resist ultrasonic cleaning and keep hydrophilicity even after heat treatment at $100{ }^{\circ} \mathrm{C}$ for $5 \mathrm{~h}$. Furthermore, a sulfobetaine copolymer bearing phenylazide group to form covalent bond by UV light irradiation showed similar electrostatic interaction with the PDMS surface. These findings will pave the way for development of a new surface modification method for PDMS.

\section{Experimental Section}

General. All chemicals were commercially available and used as received without additional purification. MPC monomer was purchased and used as received. All aqueous solutions were prepared using pure water obtained from a Millipore system. PDMS used in this work was Silicone Rubber Sheet, AS ONE $1.0 \mathrm{t} \times 30 \mathrm{x}$ $10 \mathrm{~mm}$. A plasma device, YHS-R, Sakigake Semiconductor Ltd. was used for surface treatment of PDMS. Contact angle was measured with a contact angle meter, Smart Contact PRO 100, Excimer Co. Ltd. within 2 min after putting droplet on PDMS.

Surface treatment with air-plasma. Surface of PDMS was treated with air-plasma before surface modification. The air-plasma irradiation condition was output:100W or 200W, pressure:50 Pa, air flow:100 mL/min, irradiation period:3 $\mathrm{min}$.

Surface modification and heat treatment of PDMS. After air-plasma treatment, the PDMS was immersed in water solution of polymers $(1 \mathrm{mg} / \mathrm{mL})$ for $10 \mathrm{~min}$. The PDMS was rinsed for $1 \mathrm{~min}$ under sonication and dried with nitrogen blowing. The modified PDMS was treated at room temperature for 4 days, $60{ }^{\circ} \mathrm{C}$ for $12 \mathrm{~h}$, or 100 ${ }^{\circ} \mathrm{C}$ for $5 \mathrm{~h}$ using a dryer.

Surface modification with covalent bond. UV light was irradiated to the modified PDMS surface for 5 min. A Hg-Xe lamp (200W, Hamamatsu Photonics K.K.) was used for UV light irradiation. After UV light irradiation, the sample was rinsed for 1 min under sonication and dried with nitrogen blowing.

AFM analysis of PDMS surface. AFM images were collected by NanoScope Illa Multi- mode AFM (Veeco Instruments Inc., Santa Barbara, CA) in tapping mode under ambient conditions. Silicon cantilevers with a nominal resonance frequency of $300 \sim 400 \mathrm{kHz}$, force constant $\sim 120 \mathrm{~N} / \mathrm{m}$, tip radius < $10 \mathrm{~nm}$ (ppp-NCH-AuD, Nano World Holding AG, Schaffhausen, Switzerland) were used in the AFM experiments. Images were analyzed using the software provided by the manufacturer.

\section{Synthesis of C2SB monomer}

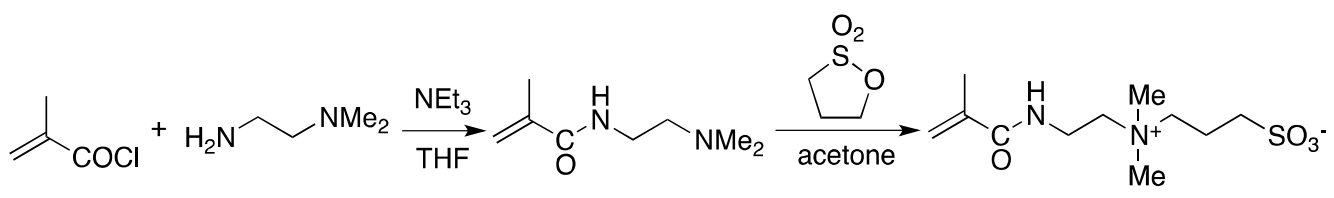

Synthesis of dimethylaminoethyl methacryl amide. To a three-necked flask, dimethylethylene diamine (1.76 $\mathrm{g}, 20 \mathrm{mmol})$, triethylamine $(4.04 \mathrm{~g}, 40 \mathrm{mmol})$, and THF $(200 \mathrm{~mL})$ were put, and the mixture was stirred at $0{ }^{\circ} \mathrm{C}$. To the mixture, a THF solution $(20 \mathrm{~mL})$ of methacryloyl chloride $(2.61 \mathrm{~g}, 25 \mathrm{mmol})$ was added dropwise. The reaction mixture was stirred at room temperature for $12 \mathrm{~h}$. The reaction mixture was poured to $5 \mathrm{wt} \%$ aqueous sodium carbonate, and the product was extracted with chloroform. After the solvent was 
evaporated, the obtained crude product was purified with silica-gel column chromatography (eluent; chloroform:methanol $=100: 2$ then 100:25 vol.): pale yellow liquid, yield 81\%. ${ }^{1} \mathrm{H}-\mathrm{NMR}\left(\mathrm{CDCl}_{3}, 400 \mathrm{MHz}\right) \delta 1.96$ $(3 \mathrm{H}, \mathrm{s}), 2.26(6 \mathrm{H}, \mathrm{s}), 2.47(2 \mathrm{H}, \mathrm{t}, \mathrm{J} 6.00 \mathrm{~Hz}), 3.39(2 \mathrm{H}, \mathrm{q}, J 5.65 \mathrm{~Hz}), 5.31(1 \mathrm{H}, \mathrm{s}), 5.70(1 \mathrm{H}, \mathrm{s}), 6.54(1 \mathrm{H}, \mathrm{s})$.

Synthesis of C2SB monomer. Dimethylaminoethyl methacryl amide (1.56 g, $10 \mathrm{mmol}$ ) and dry acetone (120 $\mathrm{mL}$ ) were put to a three-necked flask, and the mixture was stirred at room temperature. To the mixture, an acetone solution $(20 \mathrm{~mL})$ of 1,3-propanesultone $(1.83 \mathrm{~g}, 15 \mathrm{mmol})$ was added, and the mixture was stirred for $48 \mathrm{~h}$ at room temperature. The solvent was evaporated, and the obtained solid was rinsed with acetone: colorless solid (The m.p. was not determined due to polymerization.), yield 78\%. ${ }^{1} \mathrm{H}-\mathrm{NMR}\left(\mathrm{CD}_{3} \mathrm{OD}, 400 \mathrm{MHz}\right) \delta$ $1.95(3 \mathrm{H}, \mathrm{s}), 2.17 \sim 2.24(2 \mathrm{H}, \mathrm{m}), 2.87(2 \mathrm{H}, \mathrm{t}, J 6.74 \mathrm{~Hz}), 3.17(6 \mathrm{H}, \mathrm{s}), 3.47(2 \mathrm{H}, \mathrm{t}, J 6.90 \mathrm{~Hz}), 3.54 \sim 3.62(2 \mathrm{H}, \mathrm{m})$, $3.70(2 \mathrm{H}, \mathrm{t}, J 6.82 \mathrm{~Hz}), 5.45(1 \mathrm{H}, \mathrm{s}), 5.76(1 \mathrm{H}, \mathrm{s})$; Anal. Calcd. for $\mathrm{C}_{11} \mathrm{H}_{22} \mathrm{~N}_{2} \mathrm{O}_{4} \mathrm{~S}: \mathrm{C}, 47.46 ; \mathrm{H}, 7.97 ; \mathrm{N}, 10.06$. Found: C, 46.83; $\mathrm{H}, 8.00 ; \mathrm{N}, 8.93 ; \mathrm{m} / \mathrm{z}: 279\left(\mathrm{M}+\mathrm{H}^{+}\right)$.

\section{Synthesis of C3SB monomer}

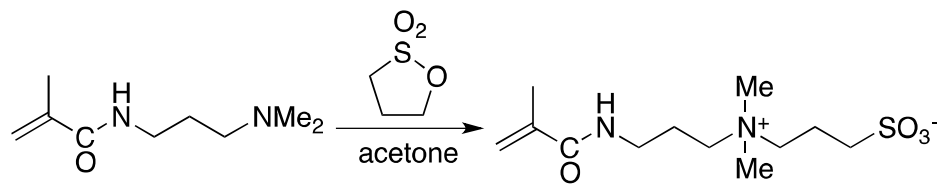

Synthesis of C3SB monomer. Dimethylaminopropyl methacryl amide (1.70 g, $10 \mathrm{mmol})$ and dry acetone (120 $\mathrm{mL}$ ) were put to a three-necked flask, and the mixture was stirred at room temperature. To the mixture, an acetone solution $(20 \mathrm{~mL}$ ) of 1,3-propanesultone $(1.83 \mathrm{~g}, 15 \mathrm{mmol})$ was added, and the mixture was stirred for $48 \mathrm{~h}$ at room temperature. The solvent was evaporated, and the obtained solid was rinsed with acetone: colorless solid (The m.p. was not determined due to polymerization.), yield 98\%. ${ }^{1} \mathrm{H}-\mathrm{NMR}\left(\mathrm{CD}_{3} \mathrm{OD}, 400 \mathrm{MHz}\right) \delta$ $1.95(3 \mathrm{H}, \mathrm{s}), 1.98 \sim 2.08(2 \mathrm{H}, \mathrm{m}), 2.14 \sim 2.24(2 \mathrm{H}, \mathrm{m}), 2.87(2 \mathrm{H}, \mathrm{t}, J 6.72 \mathrm{~Hz}), 3.10(6 \mathrm{H}, \mathrm{s}) 3.31 \sim 3.56(6 \mathrm{H}, \mathrm{m}), 5.41$ $(1 \mathrm{H}, \mathrm{s}), 5.74(1 \mathrm{H}, \mathrm{s})$; Anal. Calcd. for $\mathrm{C}_{12} \mathrm{H}_{24} \mathrm{~N}_{2} \mathrm{O}_{4} \mathrm{~S}: \mathrm{C}, 49.29 ; \mathrm{H}, 8.27 ; \mathrm{N}, 9.58$. Found: C, 48.93; H, 8.44; N, 9.28; m/z: 293 $\left(\mathrm{M}+\mathrm{H}^{+}\right)$.

\section{Synthesis of C6SB monomer}

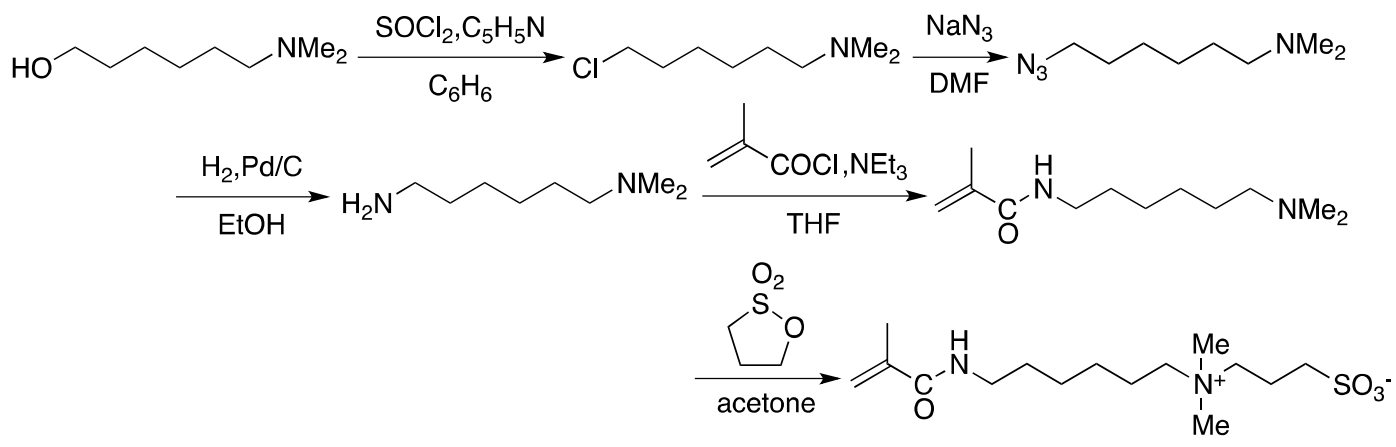

Synthesis of dimethylaminohexyl chloride. To a three-necked flask, 6-dimethylamino hexanol (14.5 g, 100 $\mathrm{mmol})$, pyridine $(9.50 \mathrm{~g}, 120 \mathrm{mmol})$, and benzene $(200 \mathrm{~mL})$ were put, and the mixture was stirred at room temperature. To the mixture, a benzene solution $(30 \mathrm{~mL})$ of thionyl chloride $(14.3 \mathrm{~g}, 120 \mathrm{mmol})$ was added dropwise, and the reaction mixture was stirred and refluxed for $12 \mathrm{~h}$. The reaction mixture was allowed to cool at room temperature, and water $(10 \mathrm{~mL})$ was added dropwise. The reaction mixture was stirred at room temperature for $1 \mathrm{~h}$, and poured into $5 \mathrm{wt} \%$ aqueous sodium carbonate. The organic layer was separated, and the solvent was evaporated. The product obtained by solvent evaporation was dried under vacuum condition, and used for the subsequent reaction without purification: pale brown liquid, yield quantitative. 
Synthesis of dimethylaminohexyl azide. Crude dimethylaminohexyl chloride (16.4 g, $100 \mathrm{mmol}$ ) and DMF (600 $\mathrm{mL}$ ) were put to a three-necked flask, and the mixture was stirred at room temperature. To the mixture, sodium azide $(13.0 \mathrm{~g}, 200 \mathrm{mmol})$ was added, and the mixture was stirred at $80{ }^{\circ} \mathrm{C}$ for $24 \mathrm{~h}$. The reaction mixture was allowed to cool at room temperature, and poured to $5 \mathrm{wt} \%$ aqueous sodium carbonate. The product was extracted with chloroform. The organic layer was acidified with conc. hydrochloric acid, and organic solvent was evaporated. To the obtained residue, $5 \mathrm{wt} \%$ aqueous sodium carbonate was poured, and the product was extracted with chloroform. The product obtained by solvent evaporation was purified with silica-gel column chromatography (eluent; chloroform:methanol $=100: 1$ then 100:10 vol.): pale brown liquid, yield 53\%. ${ }^{1} \mathrm{H}-\mathrm{NMR}\left(\mathrm{CDCl}_{3}, 400 \mathrm{MHz}\right) \delta 1.28 \sim 1.66(8 \mathrm{H}, \mathrm{m}), 2.22(6 \mathrm{H}, \mathrm{s}), 2.25(2 \mathrm{H}, \mathrm{t}, \mathrm{J} 7.44 \mathrm{~Hz}), 3.26(2 \mathrm{H}, \mathrm{t}, \mathrm{J} 6.94$ $\mathrm{Hz}$ ).

Synthesis of dimethylaminohexyl amine. To an autoclave, dimethylaminohexyl azide (8.51 $\mathrm{g}, 50 \mathrm{mmol})$, palladium carbon $(5 \mathrm{wt} \%, 1.00 \mathrm{~g})$, and ethanol $(150 \mathrm{~mL})$ were put, and the autoclave was sealed. Hydrogen was introduced to the autoclave, and the reaction mixture was stirred at room temperature for $6 \mathrm{~h}$ under 8 atm hydrogen atmosphere. The autoclave was depressurized, and the reaction mixture was filtrated to remove palladium carbon. The product obtained by solvent evaporation was dried under vacuum condition, and used for the subsequent reaction without purification: colorless liquid, yield $90 \% .{ }^{1} \mathrm{H}-\mathrm{NMR}\left(\mathrm{CDCl}_{3}\right.$, $400 \mathrm{MHz})$ ? 1.28 1.62 (8H, m), $2.27(6 \mathrm{H}, \mathrm{s}), 2.33(2 \mathrm{H}, \mathrm{t}, J 7.56 \mathrm{~Hz}), 2.78(2 \mathrm{H}, \mathrm{t}, J 7.18 \mathrm{~Hz})$.

Synthesis of dimethylaminohexyl methacryl amide. To a three-necked flask, dimethylaminohexyl amine (2.89 $\mathrm{g}, 20 \mathrm{mmol})$, triethylamine $(4.04 \mathrm{~g}, 40 \mathrm{mmol})$, and THF $(200 \mathrm{~mL})$ were put, and the mixture was stirred at $0{ }^{\circ} \mathrm{C}$. To the mixture, a THF solution $(20 \mathrm{~mL})$ of methacryloyl chloride $(2.61 \mathrm{~g}, 25 \mathrm{mmol})$ was added dropwise. The reaction mixture was stirred at room temperature for $12 \mathrm{~h}$. The reaction mixture was poured to $5 \mathrm{wt} \%$ aqueous sodium carbonate, and the product was extracted with chloroform. After the solvent was evaporated, the obtained crude product was purified with silica-gel column chromatography (eluent; chloroform:methanol = 100:5 then 100:25 vol.): pale yellow liquid, yield 94\%. ${ }^{1} \mathrm{H}-\mathrm{NMR}\left(\mathrm{CDCl}_{3}, 400 \mathrm{MHz}\right) \delta 1.26 \sim 1.59(8 \mathrm{H}, \mathrm{m}), 1.96(3 \mathrm{H}$, s), $2.26(6 \mathrm{H}, \mathrm{s}), 2.31(2 \mathrm{H}, \mathrm{t}, \mathrm{J} 7.62 \mathrm{~Hz}), 3.29(2 \mathrm{H}, \mathrm{q}, J 6.72 \mathrm{~Hz}), 5.31(1 \mathrm{H}, \mathrm{s}), 5.67(1 \mathrm{H}, \mathrm{s})$.

Synthesis of C6SB monomer. Dimethylaminohexyl methacryl amide $(2.12 \mathrm{~g}, 10 \mathrm{mmol}$ ) and dry acetone (120 $\mathrm{mL}$ ) were put to a three-necked flask, and the mixture was stirred at room temperature. To the mixture, an acetone solution $(20 \mathrm{~mL})$ of 1,3-propanesultone $(1.83 \mathrm{~g}, 15 \mathrm{mmol})$ was added, and the mixture was stirred for $48 \mathrm{~h}$ at room temperature. The solvent was evaporated, and the obtained solid was rinsed with acetone: colorless solid (The m.p. was not determined due to polymerization.), yield 52\%. ${ }^{1} \mathrm{H}-\mathrm{NMR}\left(\mathrm{CD}_{3} \mathrm{OD}, 400 \mathrm{MHz}\right) \delta$ 1.36 1.83 (8H, m), $1.93(3 \mathrm{H}, \mathrm{s}), 2.13^{\sim} 2.24(2 \mathrm{H}, \mathrm{m}), 2.87(2 \mathrm{H}, \mathrm{t}, J 6.78 \mathrm{~Hz}), 3.09(6 \mathrm{H}, \mathrm{s}), 3.21 \sim 3.55(6 \mathrm{H}, \mathrm{m}), 5.35$ $(1 \mathrm{H}, \mathrm{s}), 5.68(1 \mathrm{H}, \mathrm{s})$; Anal. Calcd. for $\mathrm{C}_{15} \mathrm{H}_{30} \mathrm{~N}_{2} \mathrm{O}_{4} \mathrm{~S}: \mathrm{C}, 53.87 ; \mathrm{H}, 9.04 ; \mathrm{N}, 8.38$. Found: C, 53.10; H, 9.03; N, 7.87; m/z: 335 $\left(\mathrm{M}+\mathrm{H}^{+}\right)$.

Polymerization procedures with AIBN. To a flask, monomer ( $5 \mathrm{mmol}), 2,2$-azobis-isobutyronitrile $(41 \mathrm{mg}, 0.25$ $\mathrm{mmol}$ or $16 \mathrm{mg}, 0.1 \mathrm{mmol}$ or $8.2 \mathrm{mg}, 0.05 \mathrm{mmol}$ ), and solvent (methanol for C2SB (45 mL), C3SB (30 mL), and C6SB $(30 \mathrm{~mL})$ monomer, a mixture of THF $(30 \mathrm{~mL})$ and methanol $(10 \mathrm{~mL})$ for MPC monomer) were put and degassed. The mixture was warmed and stood at $60{ }^{\circ} \mathrm{C}$ for $12 \mathrm{~h}$. To the reaction mixture, methanol $(30 \mathrm{~mL})$ was added. The reaction mixture was stood for overnight, and the polymer obtained as precipitate was collecterd and rinsed with methanol. The yields of polymers were $88,83,93,88,82,77,38 \%$, and quantitative for C2SB, C2SB-2, C3SB, C3SB-2, C3SB-3, C3SB-4, C6SB, and MPC, respectively. The polymers were colorless solid. In NMR measurements, peaks derived from monomers were not observed in all polymers.

Polymerization procedures with mechano-chemical reaction. To a jar (1.5 mL, stainless steel), C3SB monomer (50 mg) was put and degassed. The jar was sealed under nitrogen atmosphere and set on a ball mill, Mixer Mill MM400, Verder Scientific $\mathrm{GmbH} \&$ Co. KG. The jar was shaken at $30 \mathrm{~Hz}$ for $2 \mathrm{~h}$ at room temperature. The 
jar was open, and the formed polymer was collected and rinsed with methanol. The polymer was colorless solid with $86 \%$ yield. In NMR measurements, peaks derived from monomer were not observed.

\section{Synthesis of copolymer}

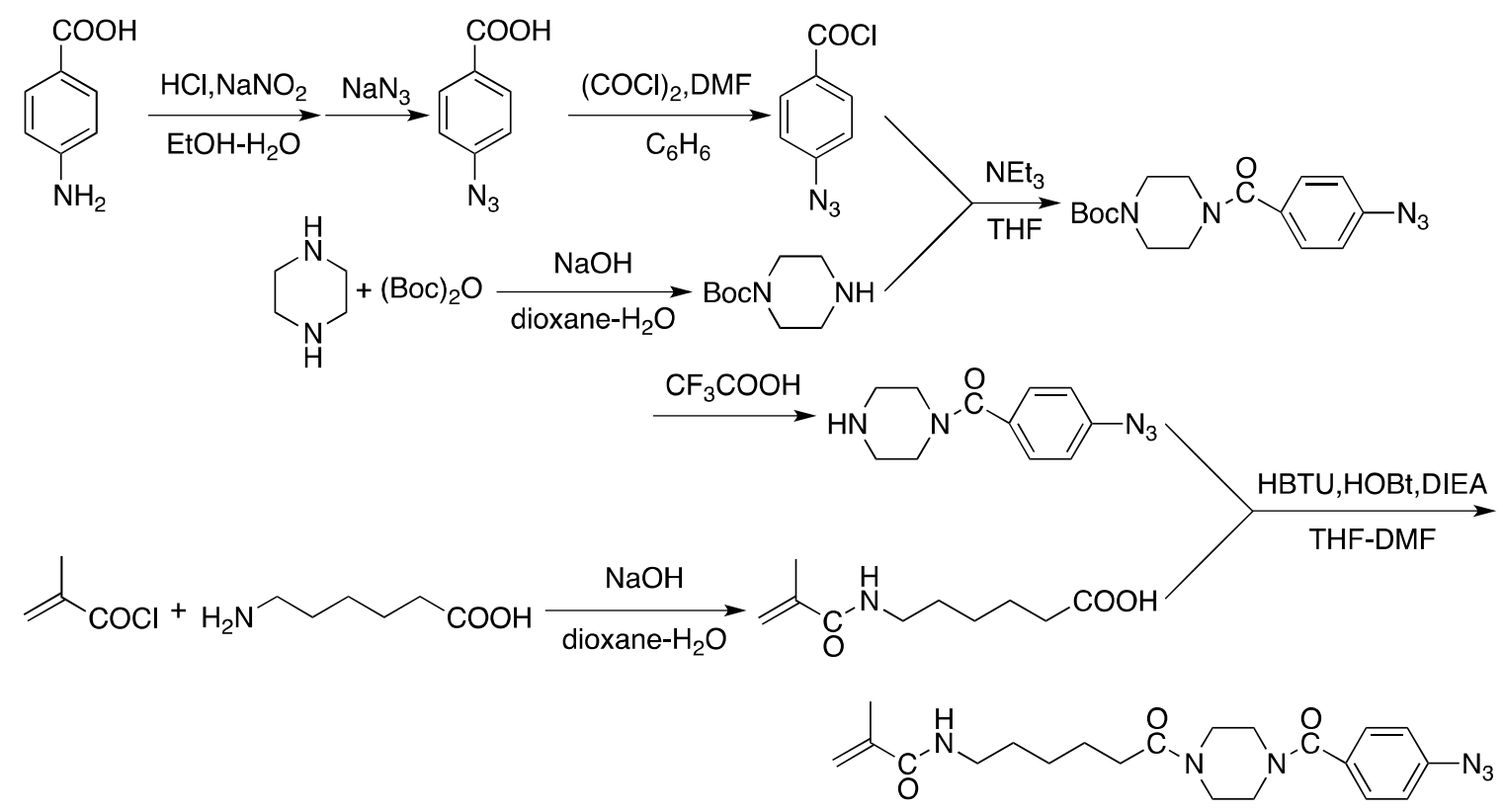

Synthesis of 4-azidobenzoic acid. To a three-necked flask, 4-aminobenzoic acid (6.86 $\mathrm{g}, 50 \mathrm{mmol})$, ethanol $(500 \mathrm{~mL})$, and conc. hydrochloric acid $(250 \mathrm{~mL})$ were put, and the mixture was stirred at $0{ }^{\circ} \mathrm{C}$. To the mixture, an aqueous solution $(100 \mathrm{~mL})$ of sodium nitrite $(5.18 \mathrm{~g}, 75 \mathrm{mmol})$ was added dropwise. The reaction mixture was stirred at $0{ }^{\circ} \mathrm{C}$ for $1 \mathrm{~h}$. This diazonium solution was kept at $0{ }^{\circ} \mathrm{C}$ for the subsequent reaction.

Sodium azide $(32.5 \mathrm{~g}, 500 \mathrm{mmol})$, ethanol $(250 \mathrm{~mL})$, and water $(250 \mathrm{~mL})$ were put into a three-necked flask, and the mixture was stirred at $0{ }^{\circ} \mathrm{C}$. To the solution, the prepared diazonium solution was added dropwise, and the reaction mixture was sirred at room temperature for $24 \mathrm{~h}$. Ethanol was evaporated, and the product was extracted with chloroform twice. The product obtained by solvent evaporation was dried under vacuum condition, and used for the subsequent reaction without purification: pale yellow solid, yield quantitative. ${ }^{1} \mathrm{H}$ NMR (CD $\left.{ }_{3} \mathrm{OD}, 400 \mathrm{MHz}\right) \delta 7.15(2 \mathrm{H}, \mathrm{d}, J 8.84 \mathrm{~Hz}), 8.04(2 \mathrm{H}, \mathrm{d}, J 8.84 \mathrm{~Hz})$.

Synthesis of 4-azidobenzoyl chloride. To a flask, 4-azidobenzoic acid (3.26g, $20 \mathrm{mmol}$ ), oxalic chloride (5.08 g, $40 \mathrm{mmol})$, and benzene $(300 \mathrm{~mL}$ ) were put, and the mixture was stirred at room temperature. To the solution, 4 drops of DMF was added, and the reaction mixture was stirred at room temperature for $6 \mathrm{~h}$. Benzene and excess oxalic chloride was evaporated, and the obtained product was dried under vacuum condition, and used for the subsequent reaction without purification: pale brown liquid, yield quantitative.

Synthesis of monoBoc-piperazine. Piperazine $(12.9 \mathrm{~g}, 150 \mathrm{mmol})$, sodium hydroxide $(1.20 \mathrm{~g}, 30 \mathrm{mmol}), 1,4-$ dioxane $(75 \mathrm{~mL})$, and water $(75 \mathrm{~mL})$ were put into a three-necked flask, and the mixture was stirred at $0{ }^{\circ} \mathrm{C}$. To the mixture, a dioxane solution $(50 \mathrm{~mL})$ of di-t-butyl dicarbonate $(6.54 \mathrm{~g}, 30 \mathrm{mmol})$ was added dropwise at 0 ${ }^{\circ} \mathrm{C}$, and the reaction mixture was stirred at room temperature for $12 \mathrm{~h}$. The reaction mixture was poured to $5 \mathrm{wt} \%$ aqueous sodium carbonate, and the product was extracted with chloroform. The product obtained by solvent evaporation was dried under vacuum condition, and used for the subsequent reaction without purification: colorless solid, yield 80\%. ${ }^{1} \mathrm{H}-\mathrm{NMR}\left(\mathrm{CDCl}_{3}, 400 \mathrm{MHz}\right) \delta 1.46(9 \mathrm{H}, \mathrm{s}), 2.81(4 \mathrm{H}, \mathrm{t}, J 4.96 \mathrm{~Hz}), 3.39(4 \mathrm{H}$, t, J $5.06 \mathrm{~Hz})$. 
Synthesis of 4-azidobenzoyl Boc-piperazine amide. To a three-necked flask, crude monoBoc-piperazine (4.95 $\mathrm{g}, 90 \%, 24 \mathrm{mmol})$, triethyl amine $(6.06 \mathrm{~g}, 60 \mathrm{mmol})$, and THF $(300 \mathrm{~mL})$ were put, and the mixture was stirred at $0{ }^{\circ} \mathrm{C}$. To the mixture, a THF solution $(50 \mathrm{~mL})$ of crude 4 -azidobenzoyl chloride $(3.63 \mathrm{~g}, 20 \mathrm{mmol})$ was added dropwise at $0{ }^{\circ} \mathrm{C}$, and the reaction mixture was stirred at room temperature for $12 \mathrm{~h}$. THF was evaporated, and obtained residue was poured to $5 \mathrm{wt} \%$ aqueous hydrochloric acid, and the product was extracted with chloroform. The product obtained by solvent evaporation was purified by GPC: pale brown solid, yield $97 \%$. ${ }^{1} \mathrm{H}-\mathrm{NMR}\left(\mathrm{CDCl}_{3}, 400 \mathrm{MHz}\right) \delta 1.47(9 \mathrm{H}, \mathrm{s}), 3.3 \sim 3.7(8 \mathrm{H}$, broad), $7.07(2 \mathrm{H}, \mathrm{d}, J 8.56 \mathrm{~Hz}), 7.42(2 \mathrm{H}, \mathrm{d}, J 8.60 \mathrm{~Hz})$.

Synthesis of 4-Azidobenzoyl Piperazine Amide. To a flask, 4-azidobenzoyl Boc-piperazine amide (3.31 g, 10 mmol) was put and stirred at $0{ }^{\circ} \mathrm{C}$. To the flask, torifluoroacetic acid $(20 \mathrm{~mL})$ was added slowly at $0{ }^{\circ} \mathrm{C}$, and the reaction mixture was stirred at room temperature for $30 \mathrm{~min}$. Trifluoroacetic acid was evaporated, and obtained residue was poured to 5 wt\% aqueous sodium carbonate, and the product was extracted with chloroform twice. The product obtained by solvent evaporation was dried under vacuum condition, and used for the subsequent reaction without purification: brown solid, yield $90 \% .{ }^{1} \mathrm{H}-\mathrm{NMR}\left(\mathrm{CDCl}_{3}, 400 \mathrm{MHz}\right) \delta 2.4 \sim 3.9$ $(8 \mathrm{H}$, broad), $7.06(2 \mathrm{H}, \mathrm{d}, J 8.56 \mathrm{~Hz}), 7.42(2 \mathrm{H}, \mathrm{d}, J 8.56 \mathrm{~Hz})$.

Synthesis of 6-methacrylamide hexanoic acid. To a three-necked flask, 6-aminohexanoic acid (2.62 g, 20 $\mathrm{mmol})$, sodium hydroxide $(800 \mathrm{mg}, 20 \mathrm{mmol}), 1,4$-dioxane $(100 \mathrm{~mL})$, and water $(100 \mathrm{~mL})$ were put and stirred at $0{ }^{\circ} \mathrm{C}$. To the mixture, a dioxane solution $(30 \mathrm{~mL})$ of methacryl chloride $(3.14 \mathrm{~g}, 30 \mathrm{mmol})$ was added dropwise at $0{ }^{\circ} \mathrm{C}$, and the reaction mixture was stirred at room temperature for $12 \mathrm{~h}$. The reaction mixture was poured to $5 \mathrm{wt} \%$ aqueous hydrochloric acid, and the product was extracted with chloroform. The product obtained by solvent evaporation was purified with silica-gel column chromatography (eluent; chloroform:methanol $=100: 1$ then 100:5 vol.): colorless liquid, yield $71 \% .{ }^{1} \mathrm{H}-\mathrm{NMR}\left(\mathrm{CDCl}_{3}, 400 \mathrm{MHz}\right) \delta$ 1.35 1.73 (6H, m), $1.96(3 \mathrm{H}, \mathrm{s}), 2.37(2 \mathrm{H}, \mathrm{t}, J \mathrm{~J} .32 \mathrm{~Hz}), 3.32(2 \mathrm{H}, \mathrm{q}, J 6.71 \mathrm{~Hz}), 5.32(1 \mathrm{H}, \mathrm{s}), 5.68(1 \mathrm{H}, \mathrm{s}), 5.89(1 \mathrm{H}$, broad).

Synthesis of (6-methacrylamide hexanoic)(4-azidobenzoylamide piperazine) amide. Under nitrogen atmosphere, 6-methacrylamide hexanoic acid (1.99 g, $10 \mathrm{mmol})$, 4-azidobenzoyl piperazine amide (2.54 g, 11 $\mathrm{mmol}$ ), 1-hydroxybenzotriazole (1.62 g, $12 \mathrm{mmol}), \mathrm{N}, \mathrm{N}$-diisopropylethylamine (1.55 g, $12 \mathrm{mmol})$, dry THF (150 $\mathrm{mL})$, and dry DMF $(50 \mathrm{~mL})$ were put to a three-necked flask, and the mixture was stirred at $0{ }^{\circ} \mathrm{C}$. To the mixture, a dry DMF solution $(40 \mathrm{~mL})$ of 2 -(1H-benzotriazole-1-yl)-1,1,3,3-tetramethyluronium hexafluorophosphate $(4.17 \mathrm{~g}, 11 \mathrm{mmol})$ was added dropwise at $0{ }^{\circ} \mathrm{C}$, and the reaction mixture was stirred at room temperature for $12 \mathrm{~h}$ under nitrogen atmosphere. Organic solvent was evaporated, and the obtained residue was poured to $5 \mathrm{wt} \%$ aqueous hydrochloric acid, and the product was extracted with chloroform. The product obtained by solvent evaporation was purified with GPC: pale yellow liquid, yield $80 \% .{ }^{1} \mathrm{H}-\mathrm{NMR}\left(\mathrm{CDCl}_{3}\right.$, $400 \mathrm{MHz}) \delta 1.33 \sim 1.72(6 \mathrm{H}, \mathrm{m}), 1.95(3 \mathrm{H}, \mathrm{s}), 2.36(2 \mathrm{H}, \mathrm{t}, J 6.98 \mathrm{~Hz}), 3.31(2 \mathrm{H}, \mathrm{q}, J 6.65 \mathrm{~Hz}), 3.3 \sim 3.8(8 \mathrm{H}, \mathrm{broad})$, $5.30(1 \mathrm{H}, \mathrm{s}), 5.68(1 \mathrm{H}, \mathrm{s}), 6.25(1 \mathrm{H}$, broad), $7.08(2 \mathrm{H}, \mathrm{d}, J 8.56 \mathrm{~Hz}), 7.44(2 \mathrm{H}, \mathrm{d}, J 8.56 \mathrm{~Hz})$; Anal. Calcd. for $\mathrm{C}_{21} \mathrm{H}_{28} \mathrm{~N}_{6} \mathrm{O}_{3}: \mathrm{C}, 61.15 ; \mathrm{H}, 6.84 ; \mathrm{N}, 20.37$. Found: $\mathrm{C}, 59.17 ; \mathrm{H}, 6.75 ; \mathrm{N}, 18.22 ; \mathrm{m} / \mathrm{z}: 413\left(\mathrm{M}+\mathrm{H}^{+}\right)$.

Copolymerization procedures. To a flask, C3SB monomer (1.46g, $5 \mathrm{mmol}),(6-$ methacrylamide hexanoic)(4azidobenzoylamide piperazine) amide (103 mg, $0.25 \mathrm{mmol}), 2,2$-azobis-isobutyronitrile (41 mg, $0.25 \mathrm{mmol}$ ), and methanol $(30 \mathrm{~mL})$ were put and degassed. The mixture was warmed and stood at $60{ }^{\circ} \mathrm{C}$ for $1 \mathrm{~h}$. To the reaction mixture, methanol $(30 \mathrm{~mL})$ was added, and the reaction mixture was stood for overnight. The copolymer obtained as precipitate was collected and rinsed with methanol. The yield of copolymer was $24 \%$ as a colorless solid, and M.W. and M.W.D. were 32000 and 4.1, respectively. In NMR measurements, peaks derived from monomers were not obserbed.

Procedures for molecular weight determination of polymers. SEC (Size Exclusion Chromatography) method was applied to molecular weight determination of polymers. SEC columns (Shodex OHpak SB-802.5 HQ and 
SB-806M HQ) for water system were used for molecular weight detrermination in the presence of $10 \mathrm{mM}$ $\mathrm{NaCl}$, and Pullulan (Shodex) was adopted as standard polyer sample to determine molecular weight.

\section{Acknowledgements}

This study was supported by grants-in-aid from the Ministry of Education, Culture, Sports, Science, and Technology (MEXT) of Japan (No. 25390022 ).

\section{References}

1. Schlenoff, J. B. Langmuir 2014, 30, 9625-9636.

https://doi.org/10.1021/la500057j

2. Deng, L.; Mrksich, M.; Whitesides, G. M. J. Am. Chem. Soc. 1996, 118, 5136-5137. https://doi.org/10.1021/ja960461d

3. Chapman, R. G.; Ostuni, E.; Takayama, S.; Holmlin, R. E.; Yan, L.; Whitesides, G. M. J. Am. Chem. Soc. 2000, 122, 8303-8304.

https://doi.org/10.1021/ja000774f

4. Ostuni, E.; Chapman, R. G.; Holmlin, R. E.; Takayama, S.; Whitesides, G. M. Langmuir 2001, 17, 56055620.

https://doi.org/10.1021/la010384m

5. Kane, R. S.; Deschatelets, P.; Whitesides, G. M. Langmuir 2003, 19, 2388-2391. https://doi.org/10.1021/la020737x

6. Iwasaki Y.; Ishihara, K. Anal. Bioanal. Chem. 2005, 381, 534-546. https://doi.org/10.1007/s00216-004-2805-9

7. Kuang, J.; Messersmith, P. B. Langmuir 2012, 28, 7258-7266. https://doi.org/10.1021/la300738e

8. Li, M.; Neoh, K. G.; Xu, L. Q.; Wang, R.; Kang, E.; Lau, T.; Olszyna, D. P.; Chiong, E. Langmuir 2012, 28, 16408-16422.

https://doi.org/10.1021/la303438t

9. Ye, S.; Jang, Y.; Yun, Y.; Shankarraman, V.; Woolley, J. R.; Hong, Y.; Gamble, L. J.; Ishihara, K.; Wagner, W. R. Langmuir 2013, 29, 8320-8327. https://doi.org/10.1021/la401341y

10. Ren, P.; Yang, H.; Liang, H.; Xu, X.; Wan, L.; Xu, Z. Langmuir 2015, 31, 5851-5858. https://doi.org/10.1021/acs.langmuir.5b00920

11. Wang, T.; Wang, X.; Long, Y.; Liu, G.; Zhang, G. Langmuir 2013, 29, 6588-6596. https://doi.org/10.1021/la401069y

12. Xiang, T.; Wang, R.; Zhao, W.; Sun, S.; Zhao, C. Langmuir 2014, 30, 5115-5125. https://doi.org/10.1021/la5001705

13. Yu, B.; Zheng, J.; Chang, Y.; Sin, M.; Chang, C. Higuchi, A.; Sun, Y. Langmuir 2014, 30, 7502-7512. https://doi.org/10.1021/la500917s

14. Ren, P.; Yang, H.; Liang, H.; Xu, X.; Wan, L.; Xu, Z. Langmuir 2015, 31, 5851-5858. https://doi.org/10.1021/acs.langmuir.5b00920 
15. Wang, T.; Kou, R.; Liu, H.; Liu, L.; Zhang, G.; Liu, G. Langmuir 2106, 32, 2698-2707. https://doi.org/10.1021/acs.langmuir.6b00293

16. Zhang, Z.; Moxey, M.; Alswieleh, A.; Morse, A. J.; Lewis, A. L.; Geoghegan, M.; Leggett, G. J. Langmuir 2016, 32, 5048-5057.

https://doi.org/10.1021/acs.langmuir.6b00763

17. Barbosa, A. I.; Reis, N. M. Analyst 2017, 142, 858-882.

https://doi.org/10.1039/C6AN02445A

18. Dawod, M.; Arvin, N. E.; Kennedy, R. T. Analyst 2017, 142, 1847-1866.

https://doi.org/10.1039/C7AN00198C

19. Ou, G. Z.; Feng, X. J.; Du, W.; Liu, X.; Liu, B. F. Anal. Bioanal. Chem. 2013, 405, 7907-7918. https://doi.org/10.1007/s00216-013-6830-4

20. Hillbog, H.; Ankner, J. F.; Gedde, U. W.; Smith, G. D.; Yasuda, H. K.; Wikstöm, K. Polymer 2000, 41, 68516863.

https://doi.org/10.1016/S0032-3861(00)00039-2

21. Kim, J.; Chaudhury, M. K.; Owen, M. J. J. Colloid Interf. Sci. 2000, 226, 231-236.

https://doi.org/10.1006/jcis.2000.6817

22. Kim, J.; Chaudhury, M. K.; Owen, M. J.; Orbeck, T. J. Colloid Interf. Sci. 2001, 244, 200-207. https://doi.org/10.1006/icis.2001.7909

23. Hillborg, H.; Tomczak, N.; Olàh, A.; Schönherr, H.; Vancso, G. J. Langmuir 2004, 20, 785-794. https://doi.org/10.1021/la035552k

24. Eddington, D. T.; Puccinelli, J. P.; Beebe, D. J. Sens. Actuators, B 2006, 114, 170-172. https://doi.org/10.1016/i.snb.2005.04.037

25. Hillborg, H.; Gedde, U. W. Polymer 1998, 39, 1991-1998.

https://doi.org/10.1016/S0032-3861(97)00484-9

26. Berdichevsky, Y.; Khandurina, J.; Guttman, A.; Lo, Y. -H. Sens. Actuators, B 2004, 97, 402-408. https://doi.org/10.1016/i.snb.2003.09.022

27. Hu, S.; Ren, X.; Bachman, M.; Sims, C. E.; Li, G. P.; Allbritton, N. Anal. Chem. 2002, 74, 4117-4123. https://doi.org/10.1021/ac025700w

28. Yeh, S.; Chen, C.; Chen, W.; Huang, C. Langmuir 2014, 30, 11386-11393. https://doi.org/10.1021/la502486e

29. Katayama, H.; Ishihama, Y.; Asakawa, N. Anal. Chem. 1998, 70, 2254-2260. https://doi.org/10.1021/ac9708755

30. Katayama, H.; Ishihama, Y.; Asakawa, N. Anal. Chem. 1998, 70, 5272-5277. https://doi.org/10.1021/ac980522I

31. Kubiak, K.; Adamczyk, Z.; Wasilewska, M. J. Colloid Interf. Sci. 2015, 457, 378-387. https://doi.org/10.1016/j.jcis.2015.07.009

32. Kunitake, T.; Tsuge, A.; Nakashima, N. Chem. Lett. 1984, 1783-1786. https://doi.org/10.1246/cl.1984.1783

33. Shimomura M.; Kunitake, T. Thin Solid Films 1985, 243-248. https://doi.org/10.1016/0040-6090(85)90474-2

34. Durán-Álvarez, A.; Maldonado-Domínguez, M.; González-Antonio, O.; Durán-Valencia, C.; Romero-Ávila, M.; Barragán-Aroche, F.; López-Ramírez, S. Langmuir 2016, 32, 2608-2616. https://doi.org/10.1021/acs.langmuir.5b04151 
35. Ge, A. Matsusaki, M.; Qiao, L.; Akashi, M.; Ye, S. Langmuir 2016, 32, 3803-3810. https://doi.org/10.1021/acs.langmuir.5b04765

36. Tanaka M.; Kurosawa, S. J. Oleo Sci. 2017, 66, 699-704. https://doi.org/10.5650/jos.ess17041

37. Chen, H.; Zhao, C.; Zhang, M.; Chen, Q.; Ma, J.; Zheng, J. Langmuir 2016, 32, 3315-3330. https://doi.org/10.1021/acs.langmuir.6b00386

38. Kuzuya, M.; Noguchi, A.; Ishikawa, M.; Koide, A.; Sawada, K.; Ito, A.; Noda, N. J. Phys. Chem. 1991, 95, 2398-2403.

https://doi.org/10.1021/j100159a052

39. Kuzuya, M.; Kondo, S.; Noguchi, A. Macromolecules 1991, 24, 4047-4053. https://doi.org/10.1021/ma00014a013

40. Leyva, E.; Platz, M. S.; Persy, G.; Wirz, J. J. Am. Chem. Soc. 1986, 108, 3783-3790. https://doi.org/10.1021/ja00273a037

41. Tanaka, M.; Sawaguchi, T.; Sato, Y.; Yoshioka, K.; Niwa, O. Langmuir 2011, 27, 170-178. https://doi.org/10.1021/la1035757 